\title{
LAND REFORMS AND ECONOMIC DEVELOPMENT
}

\author{
Hans Gersbach \\ Center of Economic Research and CEPR, ETH Zurich \\ LARS-H. R. SiemerS \\ RWI Essen
}

We examine the nexus between land transfers and human capital formation. A sequence of land redistributions enables the beneficiaries to educate their children and thus to escape from poverty. A successful land reform allows the transition of a society from an agriculture-based state of poverty to a human capital-based developed economy. We find that a temporary state of inequality among the poor is unavoidable. Finally, we discuss the political economy of land reform, whether access to land markets should be allowed for beneficiaries of land reforms, and property rights issues.

Keywords: Poverty, Land Reforms, Land Market Access, Transition

\section{INTRODUCTION}

\subsection{Motivation}

Half the world's population lives on less than 2 U.S. dollars per day [WDI (2004)] and 19\% (980 million) on less than 1 U.S. dollar [UN (2007)]. The first of the Millennium Development Goals of the United Nations stipulates that the proportion of people who live on less than 1 U.S. dollar a day and the proportion who suffer from hunger should be halved by 2015 . Seventy five percent of these people live in rural regions, and in many underdeveloped countries agriculture is the largest sector of the economy [Burgess and Stern (1993, p. 784)]. Therefore policies combating poverty need to focus largely on rural areas where agriculture is prevalent and land is an important factor in production. Inefficient land use is widespread in developing countries and the lack of land ownership is one major source of poverty [Ravallion and Sen (1994)]. Hence, land reforms may be beneficial in the fight against poverty.

At the same time, underinvestment in human capital is widespread in developing economies. About 774 million adults worldwide are illiterate, and more than

\footnotetext{
We would like to thank Christian Amon, Olaf Hölzer, Panu Poutvaara, Michael Rimmler, Julian Spiegel, two anonymous referees, an anonymous associate editor, and participants at the Annual Meeting of the Verein für Socialpolitik in Zurich in 2003 and the 59th European Meeting of the Econometric Society (ESEM) 2004 in Madrid, as well as participants at seminars at the CEBR in Copenhagen and at the University of Heidelberg, for very helpful discussion and comments. Address correspondence to: Lars Siemers. Department of Public Finance, RWI Essen, Hohenzollernstrasse 1-3, 45128 Essen, Germany; e-mail: siemers@ rwi-essen.de and Hans Gersbach, Center of Economic Research, ETH Zurich, ZUE D7, 8092 Zurich, Switzerland; e-mail: hgersbach@ethz.ch.
} 
764 million of them live in developing countries. Thus nearly $23 \%$ of the people in developing countries are illiterate. The highest illiteracy rate is found in subSaharan Africa, where the figure is 40.8\% [UNESCO (2007)]. Therefore, what is required for overcoming poverty is a strategy inducing human-capital formation in agrarian societies. In accord with this, Johnson (1997) found that a major determinant of success in the transformation of the United States from a poor agriculture-based to a wealthy industrial nation was bringing education to all levels of the rural community.

In this paper we examine whether and how land reforms can engineer a transition from backwardness to literacy and growth. Our analysis starts from the main insights of unified growth theory [Galor and Weil (2000); Galor (2005)] that human-capital formation played an important role in the transition from stagnation to growth. The rise in the demand for human capital in the process of industrialization and its effect on human-capital formation, technological progress, and the onset of the demographic transition were the main triggers in the transition from stagnation to growth. As the demand for human capital emerged, variations in human-capital formation and therefore in the rate of technological progress and the timing of the demographic transition significantly affected the distribution of income in the world economy. We suggest that land reforms can be a critical force in human-capital formation.

\subsection{The Economic Problem}

The economic problem we are analyzing is based on two subproblems. First, in developing countries, children cannot attend school because they have to contribute to family income by child labor to ensure survival. Perfect capital markets would enable parents to borrow against expected future earnings achieved by education and thus to invest in the human capital of their children. However, the poor in developing countries do usually not have access to capital markets, and the children's education must be financed by the household's current earnings and assets. Insufficient income and assets lead to the failure of human capital formation, which then perpetuates itself. The second subproblem is that developing countries often lack an effective tax system [Burgess and Stern (1993)]. Such governments cannot generate direct income support for the poor via taxes and subsidies. As developing countries are mostly agrarian economies, the most important asset and source of income is land. Consequently, land transfers may represent a practicable alternative to direct income transfers in countries that do not have an effective financial administration.

Because rural poverty and lack of land ownership go hand in hand [Ravallion and Sen (1994)], it follows that land reforms are a promising tool in fighting poverty and the associated problems of education and child labor. This is the focus of the paper.

To analyze the ways of designing a land reform that will enable a society to overcome poverty, we consider a two-sector economy with overlapping 
generations, where each generation consists of a continuum of individuals. Parents may have altruistic preferences regarding their children, but they will only invest in the education of their children if their income exceeds a particular level. Land enables households to enter a higher income bracket, which may ensure education for children and reduce poverty.

Evidence from reforms in India and the Philippines supports our model. These land reforms had a strong impact on investment in human and physical capital and on the long-term growth of income, productivity, and investment [Deininger et al. (2000, 2007)]. Therefore, successful land reforms can engineer a transition from stagnation to growth via human-capital formation.

\subsection{Results}

Our main results are as follows: Successful land reforms consist of a sequence of land transfers. To accumulate human capital, only a (small) part of the society should receive land transfers at a particular point in time. This enables beneficiaries to receive land of sufficient size. A temporary state of inequality among the poor is thus unavoidable. A successful land reform allows the transition of a society from an agriculture-based state of poverty to a human capital-based developed economy.

Moreover, allowing open access to land markets increases efficiency in rural production, but due to socially adverse land sales, may induce a decline of humancapital formation. This may cause the failure of the reform. Therefore beneficiaries of land reforms ought not to be allowed to sell land for a particular period of time. Land purchases, however, should not be restricted. Finally, we identify the political barriers to land reforms and we discuss the property rights issues.

The remainder of the paper is organized as follows: In the next section we outline the link to the relevant literature. Section 3 introduces the model. Section 4 gives an analysis of how a successful land reform needs to be designed and of the consequences the reform may have for transition and inequality. In Section 5 important extensions are discussed. Section 6 concludes.

\section{RELATION TO THE LITERATURE}

Our paper is related to several strands of the literature. Our focus on human capital in a model with a poverty trap goes back to Galor and Zeira (1993). In an environment where the capital market is imperfect and human capital investment is indivisible, the distribution of wealth affects the macroeconomic outcome, as households with insufficient wealth do not invest in human capital. This link also appears in our model. ${ }^{1}$ For developing countries, Deininger and Olinto (2000) and Bigsten and Levin (2005) state that due to credit rationing, major inequality in asset distribution seems harmful for growth. Our results suggest that temporary inequality of land holdings and income among the poor is necessary to induce growth. Our paper provides an alternative perspective to Galor et al. (2009), who 
show that inequality in the distribution of land ownership adversely affects the promotion of human capital and the pace of the transition from an agricultural to an industrial economy.

There are only a few formal land-reform models. Gersovitz (1976) and Bell (2003) stress that the effect of land reforms on aggregate output and factor prices is ambiguous and depends on particular conditions. Unlike our work, these analyses are static. Dasgupta and Ray $(1986,1987)$ and Ray and Streufert (1993) show that unemployment and undernourishment may be rooted in inequality of initial land ownership. This suggests that land reforms can mitigate unemployment and undernourishment. In a way similar to our results, they find that small land transfers will have no long-term growth effect. Moene (1992) also emphasizes the connection between labor productivity and nourishment, but demonstrates that due to general equilibrium effects, land reforms may only reduce poverty in countries where land is scarce. Finally, within a cooperative game theory approach, Horowitz (1993) considers a model where agents can decide to accept a land reform proposal or enter a conflict. Similarly to our findings, the optimal reform proposed by Horowitz consists of a sequence of redistributions. However, whereas Horowitz's aim is to prevent social conflict, our aim is to overcome poverty traps and describe how the sequence of land redistributions should be designed so that human capital formation and growth will occur. Hence our objective transcends the generation of a more egalitarian distribution of landownership.

Our paper is complementary to a recent paper by Proto (2007), who shows that tenurial contracts in agriculture can be an initial source of wealth accumulation for dynasties of the poor and can help to educate offspring. This process enables the economy to develop into a modern form. Our model shares the perspective of Proto's model, indicating that agrarian reform can have important effects on other sectors. We examine how a sequence of land reforms can move a poor economy toward literacy and growth, taking into account the human capital accumulation and migration to the manufacturing sector induced by such reforms.

Discussion of the main issues connected with land reforms has been provided in excellent survey articles, for example by de Janvry and Sadoulet (1996), Banerjee (1999), Deininger (1999), Deininger and May (2000), and Conning and Robinson (2001). This literature suggests that access to assets such as land improves access to credit markets because land can be used as collateral, can provide benefits as insurance against consumption fluctuations, and enables the poor to undertake indivisible productive investments. Overall, land reforms should improve equity, efficiency, and hence aggregate growth. Such benefits have also been stressed by agricultural economists [e.g., Tomich et al. (1995)]. However, complementary investments in education or infrastructure are required to secure the success of land reforms [e.g., Finan et al. (2005)]. Our analysis suggests that only a sequence of partial land transfers with restrictions to selling land can achieve the gains associated with such a reform.

There are also a vast number of empirical studies reviewing historical land reforms and their outcomes [see Deininger and Feder (1998); Alston et al. 
(1999, 2000); Deininger (1999); Díaz (2000); Fearnside (2001); Benjamin and Brandt (2002)]. Platteau (1992), Attwater (1997), Deininger and Feder (1998), and Fearnside (2001) stress the importance of the role played by well-defined property rights and identify the advantages of some communally owned property. Finally, new types of land reform are discussed by Banerjee (1999), Deininger (1999), and Besley and Burgess (2000). Key sources of land reform failure have been imperfect capital, insurance, and land markets that have led to insufficient investments, made macroeconomic shocks very dangerous for land reform beneficiaries, and forced corresponding distress sales. Additionally, the beneficiaries' lack of knowledge about agriculture has reinforced the danger of failure. We argue that, even without distress sales, open access to land sales markets may endanger the overall success of a land reform.

\section{MODEL}

Our model builds on Galor and Zeira (1993), Basu (1999), and Bell and Gersbach (2009). Consider an OLG structure in which individuals live for two periods: childhood and adulthood. Each generation consists of a continuum of households represented by the interval $[0,1]$. Each individual gives birth to one child. Thus each household is a family comprising one adult and one child. Each individual is endowed with one unit of time. Adults spend all their time working. Children's time is used partly for child labor and partly for attending school. Time is indexed by $t(t=0,1,2, \ldots)$.

\subsection{Human Capital Formation}

An adult $i \in[0,1]$ possesses $\lambda_{i t}$ efficiency units of labor in period $t$, where $\lambda \geq 1$ is a natural measure of an adult's human capital. $\lambda=1$ represents pure, unskilled labor. Human capital is formed in childhood by schooling. Let the portion of childhood devoted to education in period $t$ be denoted by $e_{i t} \in[0,1]$. The residual time, $1-e_{i t}$, is used for child labor. Additionally, in the course of rearing a child, the adult provides the child with a certain capacity to build human capital for adulthood and thus reinforces the effect of schooling. We assume that this additional effect increases with the level of the parents' human capital, $\lambda_{i t}$. The child's endowment of efficiency units of labor on reaching adulthood at time $t+1$ is assumed to be given by the following relationship:

$$
\lambda_{i, t+1}=1+h\left(e_{i t}\right) \lambda_{i t}
$$

The function $h\left(e_{i t}\right)$ measures the effect of school attendance $e_{i t}$ on human capital formation and is assumed to be a continuous, increasing, and differentiable function on $[0,1]$; that is, $h^{\prime}\left(e_{i t}\right)>0$ for all $e_{i t} \in[0,1)$. We presume that $h(0)=0$. Equation (1) in combination with the assumption $h(0)=0$ implies that $\lambda_{i, t+1}=1$ unless $e_{i t}>0$. 


\subsection{Production}

There is one aggregated consumption good that is produced in two sectors. The first sector is a land-based sector, such as agriculture, producing output solely by using land and effective labor (human capital). Henceforth this will be termed the agricultural sector and denoted by $A$. We assume that all farms are familybased. Household $i$ 's possession of land in period $t$ is denoted by $n_{i t}$. Besides the adult's level of human capital $\lambda_{i t}$, each child is endowed with human capital at the level $\gamma \in(0,1)$. Thus the total supply of effective labor of a household is $\left[\lambda_{i t}+\left(1-e_{i t}\right) \gamma\right]$. The farm output in period $t$ of household $i$, denoted by $y_{i t}^{A}$, is described by the production function ${ }^{2}$

$$
y_{i t}^{A}=B_{1}\left[\lambda_{i t}+\left(1-e_{i t}\right) \gamma\right]^{\alpha} \cdot\left(n_{i t}\right)^{1-\alpha},
$$

where $B_{1}$ represents the technical status quo of the sector and $\alpha \in(0,1)$ the production elasticity of the human capital input.

The second sector is solely human capital-based, and represents the industrial and service sector. Henceforth this sector will be called sector $I$. Family farmers cannot simultaneously work part-time in sector $I$. Hence labor is segmented into workers in sector $I$ and the family farm group in sector $A .{ }^{3}$ We assume a proportional relationship between output and input of effective labor. $B_{2}$ represents the fixed productivity of a unit of effective labor. Accordingly, output per household $i$ in period $t$, labeled $y_{i t}^{I}$, is given by

$$
y_{i t}^{I}=B_{2}\left[\lambda_{i t}+\left(1-e_{i t}\right) \gamma\right] .
$$

Neglecting production costs, $y_{i t}^{j}$ is equal to household income in sector $j$ ( $j \in$ $\{A, I\})$.

\subsection{Household Behavior}

Consumption and education. The allocative decision of a household is determined by the household adult. The adult's decision concerning consumption and education is determined by utility maximization. The level of utility of adult $i$ in period $t$ is denoted by $u_{i t}$. We assume that utility is determined by the period's consumption $c_{i t}$ and by the level of education of the child: $u_{i t}=u\left(c_{i t}, e_{i t}\right)$. That is, parents are altruistic and derive utility from the child's schooling time $e_{i t} \cdot{ }^{4} \mathrm{We}$ assume that adults have identical concave utility functions. Our major assumption is that capital markets are imperfect, so poor households cannot borrow against future earnings [cf. Ray (1998, chap. 14); Baland and Robinson (2000); Ranjan (2001); Basu (2003, chap. 13); Bell (2003, chap. 15)]. ${ }^{5}$ Thus the household's budget constraint in sector $j$ is $c_{i t}=y_{i t}^{j}$. In sector $A$ the household's income is given by $y_{i t}^{A}=y^{A}\left(n_{i t}, \lambda_{i t}, e_{i t}\right)$, and in sector $I$ we have $y_{i t}^{I}=y^{I}\left(\lambda_{i t}, e_{i t}\right)$. Hence 
the problem of household $i$ can be stated as follows:

$$
\max _{\left\{c_{i t}, e_{i t}\right\}} u\left(c_{i t}, e_{i t}\right) \quad \text { s.t. } \quad c_{i t}=y_{i t}^{j} \quad \text { and } \quad 0 \leq e_{i t} \leq 1 .
$$

We denote the solution of the household problem by $\left(e_{i t}^{o}, c_{i t}^{o}\right)$. Following Basu and Van (1998) and many others, we assume that there will be no option but to put the child to work full time if $y_{i t}^{j}$ is very small. At sufficiently high values of $y_{i t}^{j}$, altruism will be operative in the sense that the parent will choose $e_{i t}>0$. With rising $y_{i t}^{j}$, affluence is finally so high that the child will attend school full-time. This concurs with Galor and Zeira (1993), who assume preferences on consumption and bequest that generate the thresholds on human capital accumulation in their setting. Following Ray and Streufert (1993), we assume that after the death of the adult the child will inherit the household land.

A typical example is provided by Stone-Geary preferences in the form

$$
u\left(c_{i t}, e_{i t}\right)= \begin{cases}\left(c_{i t}-g\right) e_{i t}+g & \text { if } \quad c \geq g \\ c_{i t} & \text { if } c<g\end{cases}
$$

for some $g>0$. Such preferences yield two consumption levels, denoted by $c^{\ell}$ (lower) and $c^{u}$ (upper), with the following properties: As long as the household's budget does not allow consumption $c_{i t}$ to be higher than $c^{\ell}$, the adult will choose full-time child labor, and the child will not attend school at all: $e_{i t}^{o}=0$. However, once $c_{i t}>c^{\ell}$ is affordable, the child will attend school at least part-time. Finally, if the household can afford a consumption level of $c_{i t} \geq c^{u}$, the child will attend school full-time and does not have to work: $e_{i t}^{o}=1$. That is, preferences exogenously determine minimum requirements for the adult's willingness to choose $e_{i t}>0$, given by $c^{\ell}$, or to choose $e_{i t}=1$, given by $c^{u}$.

As both thresholds determine boundary solutions $\left(e_{i t}^{o}=0\right.$ and $\left.e_{i t}^{o}=1\right)$, it is easy to find the corresponding income thresholds. In sector $A$, income is determined by the adult's level of human capital, land ownership, and child labor, whereas in sector $I$, income is solely determined by the adult's level of human capital and child labor. For our Stone-Geary preferences we directly obtain $c^{\ell}=g$. When we maximize (5) for $c \geq g$ with respect to $e_{i t}$ and subject to $c_{i t}=y_{i t}^{I}$, we obtain $e_{i t}^{o}=\min \left\{\frac{1}{2}\left(1+\lambda_{i t} / \gamma-g / B_{2} \gamma\right), 1\right\}$. Therefore $\lambda^{\ell_{I}}=g / B_{2}-\gamma, \lambda^{u_{I}}=g / B_{2}+\gamma$, $c^{\ell}=g$, and $c^{u}=B_{2} \lambda^{u_{I}}=c^{\ell}+B_{2} \gamma$.

For our purposes, it is sufficient to know that the two threshold levels $c^{\ell}$ and $c^{u}$ exist and are determined by the preferences and technology parameters. We summarize our assumptions as follows:

(i) In sector $I$, the two critical consumption levels $c^{\ell}$ and $c^{u}$ are associated with human capital levels

$$
\begin{gathered}
\lambda^{\ell_{I}}=\frac{c^{\ell}}{B_{2}}-\gamma \\
\lambda^{u_{I}}=\frac{c^{u}}{B_{2}}
\end{gathered}
$$


such that $e_{i t}^{o}=0$ for $\lambda_{i t} \leq \lambda^{\ell_{I}}, 0<e_{i t}^{o}<1$ for $\lambda^{\ell_{I}}<\lambda_{i t}<\lambda^{u_{I}}$, and $e_{i t}^{o}=1$ for $\lambda_{i t} \geq \lambda^{u_{I}}$. The optimal educational choice $e^{o}\left(\lambda_{i t}\right)$ is strictly monotonically increasing in $\lambda_{i t}$ on the interval $\left(\lambda^{\ell_{I}}, \lambda^{u_{I}}\right)$.

(ii) In sector $A$, the two critical consumption levels $c^{\ell}$ and $c^{u}$ are associated with the human capital levels ${ }^{6}$

$$
\begin{aligned}
& \lambda^{\ell_{A}}\left(n_{i t}\right)=\left[\frac{c^{\ell}}{B_{1}\left(n_{i t}\right)^{1-\alpha}}\right]^{1 / \alpha}-\gamma \\
& \lambda^{u_{A}}\left(n_{i t}\right)=\left[\frac{c^{u}}{B_{1}\left(n_{i t}\right)^{1-\alpha}}\right]^{1 / \alpha}
\end{aligned}
$$

such that $e_{i t}^{o}=0$ for $\lambda_{i t} \leq \lambda^{\ell_{A}}\left(n_{i t}\right), 0<e_{i t}^{o}<1$ for $\lambda^{\ell_{A}}\left(n_{i t}\right)<\lambda_{i t}<\lambda^{u_{A}}\left(n_{i t}\right)$, and $e_{i t}^{o}=1$ for $\lambda_{i t} \geq \lambda^{u_{A}}\left(n_{i t}\right)$. The optimal educational choice $e^{o}\left(\lambda_{i t}, n_{i t}\right)$ is strictly monotonically increasing in $\lambda_{i t}$ on the interval $\left(\lambda^{\ell_{A}}\left(n_{i t}\right), \lambda^{u_{A}}\left(n_{i t}\right)\right)$.

Some remarks about the impact of land holdings in sector $A$ are apposite at this point. Although the solution is solely determined by the level of the adult's human capital $\lambda_{i t}$ in sector $I$, it is additionally determined by the level of land ownership $n_{i t}$ in sector $A$. The larger the amount of land owned, the less human capital is required for a given schooling level. Consequently, for sufficiently high $n_{i t}$, household consumption is higher than $c^{\ell}$ even for $\lambda_{i t}=1$, so that $e_{i t}^{o}>0$ will be chosen. ${ }^{7}$ Additionally, with high enough $n_{i t}$, even $e_{i t}^{o}=1$ is chosen for all levels of $\lambda_{i t} \geq 1 .{ }^{8}$ We define the corresponding levels of land, given a certain level of human capital, by $n^{\ell}\left(\lambda_{i t}\right)$ and $n^{u}\left(\lambda_{i t}\right)$ respectively:

$$
\begin{aligned}
& n^{\ell}\left(\lambda_{i t}\right)=\left[\frac{c^{\ell}}{B_{1}\left(\lambda_{i t}+\gamma\right)^{\alpha}}\right]^{1 /(1-\alpha)} \\
& n^{u}\left(\lambda_{i t}\right)=\left[\frac{c^{u}}{B_{1}\left(\lambda_{i t}\right)^{\alpha}}\right]^{1 /(1-\alpha)}
\end{aligned}
$$

Location and migration. Finally, we need to analyze the household's sector choice. To distinguish location, we introduce variable $a_{i t}$, which takes the value 1 if household $i$ is located in sector $A$ and 0 if household $i$ is in sector $I$. We assume that the migration decision depends solely on sectoral income comparison, given the household's endowment with land, $n_{i t}$, and human capital, $\lambda_{i t}$. Households move between the sectors without cost. For the decision, it makes a difference whether there are land markets or not. We start with the scenario without a land market. We obtain

$$
a_{i t}= \begin{cases}0 & \text { if } \frac{\lambda_{i t}+\left(1-e_{i t}^{o}\right) \gamma}{n_{i t}}>\left(\frac{B_{1}}{B_{2}}\right)^{1 /(1-\alpha)} \\ 1 & \text { otherwise. }\end{cases}
$$

Equation (8) determines a $\tilde{\lambda}\left(n_{i t}\right)$ such that, as long as $\lambda_{i t}<\tilde{\lambda}\left(n_{i t}\right)$, household $i$ is located in sector $A$, otherwise in sector $I$. Therefore if a low-educated adult 
does not possess a sufficient amount of land, he will work as a low-skilled laborer in sector $I$. Due to decreasing marginal returns in sector $A$, however, sector $I$ turns out to be an attractive alternative for educated households as well, as soon as human capital intensity per unit of land, $\lambda_{i t} / n_{i t}$, becomes high enough.

Hence there are three groups of households: landless and uneducated households in sector $I$; land-owning households with a low or medium level of human capital in sector $A$; and households with a high level of human capital in sector $I$.

\subsection{Dynamics}

In principle, the dynamics are the same in both sectors. To establish the dynamics we have to analyze (1) in the light of our assumptions concerning household behavior:

$$
\lambda_{i, t+1}= \begin{cases}1 & \forall \lambda_{i t} \leq \lambda^{\ell_{j}} ; \\ 1+h\left(e_{i t}^{o}\right) \lambda_{i t} & \forall \lambda_{i t} \in\left(\lambda^{\ell_{j}}, \lambda^{u_{j}}\right) ; \\ 1+h(1) \lambda_{i t} & \forall \lambda_{i t} \geq \lambda^{u_{j}},\end{cases}
$$

where $j=\{A, I\}, \lambda^{\ell_{A}}=\lambda^{\ell_{A}}\left(n_{i t}\right)$, and $\lambda^{u_{A}}=\lambda^{u_{A}}\left(n_{i t}\right)$; moreover, we have $e_{i t}^{o}=e_{i t}^{o}\left(\lambda_{i t}, n_{i t}\right)$ in sector $A$ and $e_{i t}^{o}=e_{i t}^{o}\left(\lambda_{i t}\right)$ in sector $I$. A detailed description of the dynamics is given in an earlier version of this article [Gersbach and Siemers (2005b)]. Here we focus on the growth case where $h(1)>1$ and $\lambda^{\ell_{j}}>1$. When a household has reached full-time schooling, human capital grows at the rate $\frac{\lambda_{i, t+1}-\lambda_{i t}}{\lambda_{i t}}=h(1)-1+1 / \lambda_{i t}$. Thus the growth rate decreases as human capital rises but increases asymptotically at the constant rate $h(1)-1>0$. Moreover, we assume that $h\left(e_{i t}^{o}\right) \lambda_{i t}$ is convex. Thus there exist one unstable stationary state at a level $\lambda^{m_{j}}$ and the locally stable "poverty-trap" stationary state at $\lambda_{i t}=1$, where $1<\lambda^{\ell_{j}}<\lambda^{m_{j}}<\lambda^{u_{j}}$. This is illustrated in Figure B.1, which is also valid for a given amount of land in sector $A$.

\section{LAND REFORM}

\subsection{Land Redistribution}

Here we examine how land reforms can be designed to overcome underdevelopment. We start with the scenario where the whole society is in a state of backwardness. In particular, we assume that each adult in starting period $t=0$ owns a plot of land of identical size $n_{-1}>0$ and that $\lambda_{i 0}=1$ for all $i \in[0,1]$. Moreover, we assume that $\lambda^{\ell_{A}}\left(n_{-1}\right)>1$. So without government intervention all adults will choose $e_{i 0}=0$ and the human capital of their offspring will remain at $\lambda_{i}=1$. Thus poverty (and child labor) perpetuates itself. ${ }^{9}$ Aggregate endowment of land in the economy is given by $N=\int_{i=0}^{1} n_{-1}(i) \mathrm{d} i$. In order to determine initial sector allocation we assume $n_{-1}>(1+\gamma)\left(B_{2} / B_{1}\right)^{1 /(1-\alpha)}$; that is, initially all households are located in the agrarian sector $A .{ }^{10}$

To examine land reforms we proceed as follows: From period $t=0$ onwards, the social planner redistributes land. We use $\left\{\bar{n}_{i t}\right\}_{i=0}^{1}$ to denote the social planner's 
redistribution scheme at the beginning of period $t$. That is, adult $i$ receives additional land $\bar{n}_{i t}$ (if $\bar{n}_{i t}>0$ ) or is forced to donate land of size $\left|\bar{n}_{i t}\right|$ (if $\bar{n}_{i t}<0$ ). Feasible land redistributions have to satisfy $\int_{0}^{1} \bar{n}_{t}(i) \mathrm{d} i=0$.

The sequence of events is as follows: At the beginning of a period $t$, an adult $i$ is endowed with human capital $\lambda_{i t}$ and land $n_{i, t-1}$. A household $i$ may or may not be selected as a beneficiary of the land reform. As a beneficiary, the household receives a plot of land of size $\bar{n}_{i t}>0$. If not selected, it may be forced to donate land to the state for redistribution. For ease of presentation, we denote the size of land expropriated from household $i$ by $n_{i t}^{\tau}$. In this case we have $\bar{n}_{i t}=-n_{i t}^{\tau}<0$. Actual land holdings in period $t$ are then given by $n_{i t}=n_{i, t-1}+\bar{n}_{i t}$. After land redistribution all adults $i \in[0,1]$ make decisions on the sector they want to work in, on consumption $c_{i t}$, and on the child's education $e_{i t}$. This cycle is repeated until the aim of the land reform is accomplished.

Because after an initial phase of nationalization in period $t=0$, the social planner redistributes land in each period $t$, we have a property rights system comparable to the system called "leasehold in judicial terms" but without any lease being charged. A household obtains land and receives full property rights. However, after a given span of time the land may fall back to the state, either wholly or in part. Recall that in our model a period is the complete productive life of an adult. Hence the redistribution scheme can be interpreted as a particular type of inheritance tax, as inherited land is a necessary condition for expropriation.

\subsection{The Optimal Land Reform}

In an attempt to educate a society as fast as possible, it is not clear a priori which land transfers are "optimal." To define our concept of optimal land reforms we assume that the size of land transferred to a beneficiary in period $t, \bar{n}_{i t}$, fulfills $e^{o}\left(\lambda_{i t}, n_{i, t-1}+\bar{n}_{i t}\right)=1$. The assumption is based on Siemers (2005) and Bell and Gersbach (2009), who provide social welfare analyses concerning the education of a society for models like ours and deduce that full-time schooling (and the absence of child labor) for beneficiaries is optimal, at least at the beginning. The minimal size of land a household must own in order to educate the child full-time, denoted by $n^{u}\left(\lambda_{i t}\right)$, is given by (7) above. We use $\bar{t}_{i}$ to denote the period in which a household $i$ receives a land gift. Hence we obtain ${ }^{11}$

$$
\lambda_{i, \bar{t}_{i}+1}=1+h(1) \lambda_{i \bar{t}_{i}}
$$

Because $\lambda_{i, t+1}>\lambda_{i t}$ and $n_{i t}=n^{u}\left(\lambda_{i t}\right)$, continuous human capital accumulation is ensured, ceteris paribus. Beneficiaries' incomes are higher than threshold $c^{u}$ and will continuously grow over time. Accordingly, the state can levy inheritance taxes via expropriation on all previous beneficiaries without endangering its overall objective. Thus, in each period, one has to check how much land the households already supported still require to sustain full-time schooling. The rest of the land can be redistributed. The maximal amount of land taken away from households 
that benefitted in the past is given by

$$
n_{i t}^{\tau}\left(\lambda_{i t}\right)=\max \left\{0, n_{i, t-1}-n^{u}\left(\lambda_{i t}\right)\right\}=\max \left\{0, n_{i, t-1}-\left(\frac{c^{u}}{B_{1} \lambda_{i t}^{\alpha}}\right)^{1 /(1-\alpha)}\right\} .
$$

If a beneficiary's level of human capital allows earning more than $c^{u}$ in sector $I$, the household will switch sector and does not need any land to avoid poverty. Thus, the social planner can even redistribute the entire land of the household.

We use $\delta_{t}$ to denote the share of households in the society that the social planner allocates land to in period $t$. Moreover, we use $\mu_{t}$ to denote the fraction of the society to which land has been allocated in a period $t$. Hence, $\mu_{t}=\sum_{k=0}^{t} \delta_{k}$ and $\delta_{t}=\mu_{t}-\mu_{t-1}$. To redistribute land, it is necessary to nationalize some land from a subset of citizens within a particular period. We assume throughout the paper that the social planner can nationalize the required amount of land within a particular period. The formal definitions are as follows:

DEFINITION 1. A society can be educated in T periods if there exists a land redistribution scheme $\left\{\left\{\bar{n}_{i t}\right\}_{i=0}^{1}\right\}_{t=0}^{T-1}$, where $\int_{0}^{1} \bar{n}_{t}(i) d i=0$, such that all households in sector A display $\lambda_{i T} \geq \lambda^{u_{A}}\left(n_{i T}\right)$ and all households in sector I display $\lambda_{i T} \geq \lambda^{u_{I}}$, so that $e_{i T}=1$ for all $i \in[0,1]$.

DEFINITION 2. Given some initial distribution of land, an optimal land reform is characterized by a sequence of land redistributions given by $\left\{\left\{\bar{n}_{i t}\right\}_{i=0}^{1}\right\}_{t=0}^{T-1}$ that fulfill (i) $e_{i T}^{o}=1$ for all $i \in[0,1] ;(i i) \int_{0}^{1} \bar{n}_{t}(i) d i=0$ for all $t=0,1, \ldots, T-1$; and (iii) there does not exist any other sequence $\left\{\left\{\bar{n}_{i t}\right\}_{i=0}^{1}\right\}_{t=0}^{T^{\prime}-1}$ with $T^{\prime}<T$ that fulfills the three conditions above.

Condition (i) formalizes a fully educated society. Condition (ii) is the land resource constraint and condition (iii) requires that no other dynamic land redistribution scheme exists that would enable the society to be educated in a shorter space of time. As we assume that beneficiaries will have total land $n^{u}\left(\lambda_{i t}\right)$, optimality is restricted to this type of land reforms. ${ }^{12}$ We obtain

PROPOSITION 1. There exists an optimal dynamic land redistribution scheme $\left\{\left\{\bar{n}_{i t}\right\}_{i=0}^{1}\right\}_{t=0}^{T-1}$. The education of a society is feasible in finite time; that is, $T<\infty$.

The proposition is proved in Appendix A. The essential features of the optimal land reform are as follows: Educated households have to give land to the state as long as this expropriation does not endanger the full-time schooling of the household's child. This enables the maximum amount of land to be distributed to those uneducated so far. This land has to be distributed to as many households as possible, with the constraint that each single supported household establishes the optimal level of schooling for the household's child. This ensures the fastest possible education process. As this policy scheme generates continued human 
capital accumulation, the number of educated households grows from period to period so that the society is educated in finite time. Note that the optimal scheme is indeterminate in the following sense: It does not matter which particular uneducated household $i$ is selected as a beneficiary in a particular period $t$. Moreover, we showed that the creation of inequality among the poor is a necessary condition for escaping from backwardness.

\subsection{Migration, Transition, and Inequality}

A beneficiary has land of size $n^{u}\left(\lambda_{i t}\right)$. He or she is thus indifferent between sector $A$ and sector $I$ if $B_{2} \lambda_{i t}=c^{u}$, so that $\tilde{\lambda}\left(n_{i t}\right)=\tilde{\lambda}=c^{u} / B_{2}=\lambda^{u_{I}}$. Hence, if $\lambda_{i t}>\lambda^{u_{I}}$ holds, a beneficiary household will switch to sector $I$. Accordingly we obtain:

PROPOSITION 2. Each beneficiary stays in sector A for $l$ periods before switching to sector $I . l$ is determined by $\min _{l>0} \quad \sum_{k=0}^{l}[h(1)]^{k}>\lambda^{u_{I}}$.

Proposition 2 follows directly from the combination of (8) and $\tilde{\lambda}=\lambda^{u_{I}} \cdot{ }^{13}$ The next two propositions complete the description of the structural change induced by the land reform.

PROPOSITION 3. Suppose that an optimal land reform is applied. Then the migration pattern in period $t>0$ is given as

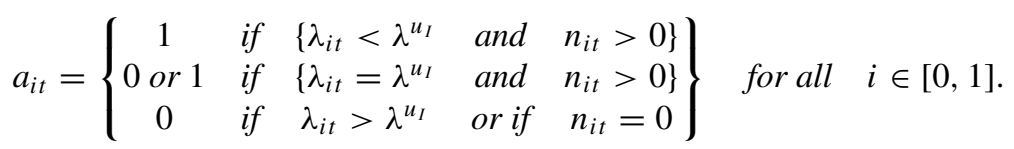

PROPOSITION 4. All households will asymptotically leave sector A and end up in sector $I$; that is, $a_{i t}=0$ for all $i \in[0,1]$ when $t \rightarrow \infty$.

That is, in the prereform era, the society is agrarian. In the course of the land reform, sector $A$ is developing via individual accumulation of human capital. When human capital reaches a critical level, sector $I$ starts to develop. Finally, sector $A$ vanishes. Over time, all households escape poverty and child labor. The proofs are given in Appendix A.

\section{EXTENSIONS}

In this section we discuss three main extensions of our framework.

\subsection{Land Markets}

Our first extension concerns land markets. This analysis is performed in our working paper [Gersbach and Siemers (2005b)]. In particular, we show there that it may be useful to restrict the access of beneficiaries to land markets temporarily. 
The reason is that the incentive to sell the land received and migrate occurs irrespective of individual skill levels. So with open access to land markets, parents may prefer to sell the land and switch sectors too early, that is, when they have not yet accumulated enough (human) capital. This will result in the failure of the land reform, as their descendants will stay in (or fall back into) the poverty trap. To prevent such inefficient land sales, a (temporary) prohibition of land sales for beneficiaries of the reform may be necessary. ${ }^{14}$

\subsection{Property Rights}

An issue for investigation is the extent to which property rights should be given to beneficiaries. The advantage of doing so is that it increases the incentive of participants to develop property and to make it more productive (effort and investment). Also, that land can be used as collateral. On the other hand, strict property rights undermine the potential for further land redistribution. In our model, beneficiaries should be given property rights for the span of a whole life, but after the death of the beneficiary generation, part of the transferred land can be confiscated again. In this way, the incentive effect of property rights can function, albeit not to the full extent. Also, for incentive reasons, it is useful to settle on a less extreme form of land redistribution where there is an upper bound on the fraction of land an owner has to give up for redistribution purposes.

\subsection{The Political Economy of Land Reforms}

The last extension concerns political barriers. The main obstacle is the dispossession of land in the first period if the government possesses no land of its own. In this period it is probably necessary for an amount of land to be taken away from powerful landlords. The group of landowners forced to donate land in the first period will vigorously oppose such actions and will have powerful incentives for halting the process via lobbying activities and vote buying. Governments therefore often renounce land reforms. In any case, it is thus useful to start with a more moderate scheme with an upper bound on the fraction of land that can be taken away. As with other forms of taxation, this upper bound should clearly be below 50\%. In all subsequent periods, however, it is possible to construct growth-enhancing redistribution schemes where land is only taken away from former beneficiaries. ${ }^{15}$ Moreover, the proportion of owners forced to donate land for redistribution purposes must be sufficiently small for a government to be able to build a stable majority in favor of a growth-enhancing redistribution scheme. Otherwise the government itself may not be interested in pursuing land reforms, because it may fear loss of power.

To improve the feasibility of our land reform, landlord households initially loosing part of their land to the state should be guaranteed that all lost land will be given back once the task of the reform is accomplished and no land redistribution 
is required anymore. Alternatively, particular forms of compensation could break the opposition of landlords [Bell (2003, pp. 408-412)].

\section{CONCLUDING COMMENTS}

There is empirical evidence indicating that a higher degree of education and more equitable land distribution may improve income distribution and enhance growth [Lundberg and Squire (2003)]. We show that land reforms are a means of inducing the transition from a society caught in a poverty trap to a developed, skill-based economy where agriculture plays a minor role. ${ }^{16}$ The optimal land reform consists of a sequence of land transfers rather than a one-time event only. Producing (temporary) inequality among the poor is a necessary condition for optimal land reforms. Inequality is required because land is scarce and land transfers have to ensure not only viable farm sizes but also adequate (human) capital formation to escape poverty traps.

Our analysis complements the insights of unified growth theory in explaining the transition from stagnation to growth via human-capital formation. Regarding the Great Diversion, this paper suggests that observed variations in human-capital formation and comparative economic development could be attributed to historical differences in the distribution of landownership across countries.

It is important to stress that land reforms may have two advantages over straight income transfers [which are analyzed, for instance, by Bell and Gersbach (2009)]: (i) In contrast to redistribution via transfers and taxes, land reforms do not require a well-functioning fiscal authority that enforces tax collection, which developing countries often lack. (ii) Direct income transfers must be repeated continuously, if one-time subsidization is not sufficient to escape poverty traps [Gersbach and Siemers (2005a); Siemers (2005, chap. 5)]. Land transfers increase income permanently and a fall-back into poverty is less likely than with income transfers. The drawbacks of land reforms are the political barriers, as discussed in the last section.

\section{NOTES}

1. See also Aghion et al. (1999), Swinnerton and Rogers (1999), Sylwester (2000), Birchenall (2001), Eicher and García-Peñalosa (2001), and Viaene and Zilcha (2003).

2. Deininger and Feder (1998, p. 16) report that a large number of empirical studies have been unable to disprove the hypothesis of constant returns to scale in agricultural production.

3. A detailed justification of this assumption can be found in Gersovitz (1976, p. 84).

4. For expositional convenience, we neglect the child's consumption. Our results can be generalized to the case where the child's consumption is a fixed fraction of the adult's consumption.

5. The literature offers various justifications for this assumption. The most important is that future human capital (and associated income) is not a means of offering credible future repayments to a potential lender.

6. Note that $\lambda^{\ell_{A}}\left(n_{i t}\right)$ and $\lambda^{u_{A}}\left(n_{i t}\right)$ are determined by $c^{\ell}=B_{1}\left[\lambda^{\ell_{A}}\left(n_{i t}\right)+\gamma\right]^{\alpha} n_{i t}^{1-\alpha}$ and $c^{u}=$ $B_{1}\left[\lambda^{u_{A}}\left(n_{i t}\right)\right]^{\alpha} n_{i t}^{1-\alpha}$.

7. Hence for high enough $n_{i t}, \lambda^{\ell_{A}}\left(n_{i t}\right)<1$, and no lower threshold exists. 
8. That is, $\lambda^{u_{A}}\left(n_{i t}\right) \leq 1$.

9. We analyze the worst case, where no household is willing to invest in education. Note that we initially have equal land distribution but a society caught in a poverty trap.

10. We could also work with alternative initial conditions in which both sectors are populated at the beginning [condition: $n_{-1}=\left(B_{2} / B_{1}\right)^{1 /(1-\alpha)}(1+\gamma)$ ] or all individuals are in the industrial sector [condition: $n_{-1}<\left(B_{2} / B_{1}\right)^{1 /(1-\alpha)}(1+\gamma)$ ]. The qualitative results in the paper would remain the same.

11. Choosing $n^{u}\left(\lambda_{i t}\right)$ means turning $\lambda_{i t}$ into $\lambda^{u_{A}}\left(n_{i t}\right)$.

12. To explore land redistribution where beneficiaries can obtain more or less land is left for future research.

13. See also equation (A.10) in Appendix A.

14. Even if we exclude distress sales due to macro shocks, open land market access may endanger the success of the reform. For different reasons, Drazen and Eckstein (1988) and Deaton and Laroque (2001) argue that land markets may be detrimental to growth, as savings in the form of land crowd out growth-enhancing capital formation. However, Deaton and Laroque demonstrate that the Golden Rule allocation can be established by nationalizing land and "renting" it out at no charge.

15. Once the process of development has passed its first stages, capitalists and landowners may, in the medium term, have an incentive to support the provision of human capital formation [Galor and Moav (2006); Poutvaara (2003)].

16. A similar transition can be found, for example, in U.S. history. Whereas at the time of independence approximately $90 \%$ of the labor force was agricultural, today only $3 \%$ of it is employed in farming [Johnson (1997)].

\section{REFERENCES}

Aghion, Philippe, Eve Caroli, and Cecilia García-Peñalosa (1999) Inequality and economic growth: The perspective of the new growth theories. Journal of Economic Literature 37(4), 16151660.

Alston, Lee J., Gary D. Libecap, and Bernardo Mueller (1999) A model of rural conflict: Violence and land reform policy in Brazil. Environment and Development Economics 4(2), 135-160.

Alston, Lee J., Gary D. Libecap, and Bernardo Mueller (2000) Land reform policies, the sources of violent conflict, and implications for deforestation in the Brazilian Amazon. Journal of Environmental Economics and Management 39(2), 162-188.

Attwater, Roger (1997) Property Entitlements and Land Reform in Upland Thai Catchments. Working Papers in Ecological Economics 9704, Australian National University, Canberra.

Baland, Jean-Marie and James A. Robinson (2000) Is child labor inefficient? Journal of Political Economy 108(4), 663-679.

Banerjee, Abhijit (1999) Land Reforms: Prospects and Strategies. Working Paper 99-24, Department of Economics, Massachusetts Institute of Technology.

Basu, Kaushik (1999) Child labor: Cause, consequence, and cure, with remarks on international labor standards. Journal of Economic Literature 37(3), 1083-1119.

Basu, Kaushik (2003) Analytical Development Economics-The Less Developed Economy Revisited. Cambridge, MA/London: MIT Press.

Basu, Kaushik and Pham Hoang Van (1998) The economics of child labor. American Economic Review $88,412-427$.

Bell, Clive (2003) Development Policy as Public Finance. Oxford, UK: Oxford University Press.

Bell, Clive and Hans Gersbach (2009) Child labor and the education of a society. Macroeconomic Dynamics 13(2), 220-249.

Benjamin, Dwayne and Loren Brandt (2002) Property rights, labor markets, and efficiency in a transition economy: the case of rural China. Canadian Journal of Economics 35(4), 689-716.

Besley, Timothy and Robin Burgess (2000) Land reform, poverty reduction, and growth: Evidence from India. Quarterly Journal of Economics 115(2), 389-430. 
Bigsten, Arne and Jörgen Levin (2005) Growth, income distribution, and poverty: A review. In Anthony F. Shorrocks and Rolph van der Hoeven (eds.), Growth, Inequality, and Poverty—Prospects for Propoor Economic Development, pp. 251-268. Oxford, UK: Oxford University Press.

Birchenall, Javier A. (2001) Income distribution, human capital and economic growth in Colombia. Journal of Development Economics 66(1), 271-287.

Burgess, Robin and Nicholas Stern (1993) Taxation and development. Journal of Economic Literature 31(2), 762-830.

Conning, Jonathan H. and James A. Robinson (2001) Land Reform and the Political Organization of Agriculture. Working Paper 160, Center for Development Economics, Williams College, Williamstown.

Dasgupta, Partha and Debraj Ray (1986) Inequality as a determinant of malnutrition and unemployment: Theory. Economic Journal 96(384), 1011-1034.

Dasgupta, Partha and Debraj Ray (1987) Inequality as a determinant of malnutrition and unemployment: Policy. Economic Journal 97(385), 177-188.

Deaton, Angus and Guy Laroque (2001) Housing, land prices, and growth. Journal of Economic Growth 6(2), 87-105.

Deininger, Klaus (1999) Making negotiated land reform work: Initial experience from Colombia, Brazil, and South Africa. World Development 27(4), 651-672.

Deininger, Klaus and Gershon Feder (1998) Land institutions and land markets. In B.L. Gardner and G.C. Rausser (eds.), Handbook of Agricultural Economics 1, 1st ed., chap. 6, pp. 288-331. Amsterdam: Elsevier.

Deininger, Klaus, Songqing Jin, and Hari K. Nagarajan (2007) Land Reforms, Poverty Reduction, and Economic Growth: Evidence from India. Policy Research Working Paper 4448, The World Bank, Washington, DC.

Deininger, Klaus and Julian May (2000) Can There Be Growth with Equity? An Initial Assessment of Land Reform in South Africa. Policy Research Working Paper 2451, The World Bank, Washington, DC.

Deininger, Klaus and Pedro Olinto (2000) Asset Distribution, Inequality, and Growth. Policy Research Working Paper 2375, The World Bank, Washington, DC.

Deininger, Klaus, Pedro Olinto, and Miet Maertens (2000) Redistribution, Investment, and Human Capital Accumulation: The Case of Agrarian Reform in the Philippines. Prepared for the Annual Bank Conference on Development Economics, The World Bank, Washington, DC.

De Janvry, Alain and Elisabeth Sadoulet (1996) Household Modeling for the Design of Poverty Alleviation Strategies. Working Paper 787, Department of Agricultural and Resource Economics, University of California at Berkeley. [Published in French in Revue d'Economie du Developpement 3(1995): 3-23.]

Díaz, Antonia (2000) On the political economy of Latin American land reforms. Review of Economic Dynamics 3, 551-571.

Drazen, Allan and Zvi Eckstein (1988) On the organization of rural markets and the process of economic development. American Economic Review 78(3), 431-443.

Eicher, Theo S. and Cecilia García-Peñalosa (2001) Inequality and growth: The dual role of human capital in development. Journal of Development Economics 66, 173-197.

Fearnside, Philip M. (2001) Land-tenure issues as factors in environmental destruction in Brazilian Amazonia: The case of southern Para. World Development 29(8), 1361-1372.

Finan, Frederico, Elisabeth Sadoulet, and Alain de Janvry (2005) Measuring the poverty reduction potential of land in rural Mexico. Journal of Development Economics 77, 27-51.

Galor, Oded (2005) From stagnation to growth: Unified growth theory. In Philippe Aghion and Steven N. Durlauf (eds.), Handbook of Economic Growth 1A, chap. 4, pp. 171-293. Amsterdam: Elsevier.

Galor, Oded and Omer Moav (2006) Das Human-Kapital: A theory of the demise of the class structure. Review of Economic Studies 73(1), 85-117. 
Galor, Oded, Omer Moav, and Dietrich Vollrath (2009) Inequality in land ownership, the emergence of human capital promoting institutions, and the Great Divergence. Review of Economic Studies 76(1), $143-179$.

Galor, Oded and David N. Weil (2000) Population, technology and growth: From Malthusian stagnation to the demographic transition and beyond. American Economic Review 90(4), 806828.

Galor, Oded and J. Zeira (1993) Income distribution and macroeconomics. Review of Economic Studies $60,35-52$.

Gersbach, Hans and Lars-H. Siemers (2005a) Can Democracy Educate a Society? IZA Discussion Paper 1693, Institute for the Study of Labor (IZA), Bonn.

Gersbach, Hans and Lars-H. Siemers (2005b) Land Reforms and Economic Development. CEPR Discussion Paper 5184, Center for Economic Policy Research (CEPR), London.

Gersovitz, M. (1976) Land reform: Some theoretical considerations. Journal of Development Studies 13(October), 79-91.

Horowitz, Andrew W. (1993) Time paths of land reform: A theoretical model of reform dynamics. American Economic Review 83(4), 1003-1010.

Johnson, D. Gale (1997) Agriculture and the wealth of nations. American Economic Review Papers and Proceedings 87(2), 1-12.

Lundberg, Mattias and Lyn Squire (2003) The simultaneous evolution of growth and inequality. Economic Journal 113(487), 326-344.

Moene, Karl Ove (1992) Poverty and landownership. American Economic Review 82(1), 52-64.

Platteau, Jean-Philippe (1992) Formalization and Privatization of Land Rights in Sub-Saharan Africa: A Critique of Current Orthodoxies and Structural Adjustment Programmes. DEP 34, London School of Economics.

Poutvaara, Panu (2003) Gerontocracy revisited: Unilateral transfer to the young may benefit the middle-aged. Journal of Public Economics 88(1-2), 161-174.

Proto, Eugenio (2007) Land and the transition from a dual to a modern economy. Journal of Development Economics 83(1), 88-108.

Ranjan, Priya (2001) Credit constraints and the phenomenon of child labor. Journal of Development Economics 64, 81-102.

Ravallion, Martin and Binayak Sen (1994) Impacts on rural poverty of land-based targeting: Further results of Bangladesh. World Development 22(6), 823-838.

Ray, Debraj (1998) Development Economics. Princeton, NJ: Princeton University Press.

Ray, Debraj and Peter A. Streufert (1993) Dynamic equilibria with unemployment due to undernourishment. Economic Theory 3(1), 61-85.

Siemers, Lars-Hinrich R. (2005) How to Overcome Poverty Traps by Education. Doctoral thesis, Ruprecht-Karls-University at Heidelberg, Available at http://www.ub.uni -heidelberg.de/archiv/5363. Accessed September 1, 2009.

Swinnerton, Kenneth A. and Carol Ann Rogers (1999) The economics of child labor: A comment. The American Economic Review 89(5), 1382-1385.

Sylwester, Kevin (2000) Income inequality, education expenditures, and growth. Journal of Development Economics 63, 379-398.

Tomich, Thomas, Peter Kilby, and Bruce F. Johnston (1995) Transforming Agrarian Economies. Ithaca, NY: Cornell University Press.

UN (2007) The Millennium Development Goals Report 2007. New York, NY: United Nations.

UNESCO (2007) EFA global monitoring report. UNESCO Institute for Statistics, database at http://gmr.uis.unesco.org. Accessed February 18, 2008.

Viaene, Jean-Marie and Itzhak Zilcha (2003) Human capital formation, income inequality and growth. In Theo S. Eicher and Stephen J. Turnovsky (eds.), Inequality and Growth: Theory and Policy Implications, chap. 4, pp. 89-117. Cambridge, MA: MIT Press.

WDI (2004) World Development Indicators 2004. Washington, DC: The World Bank. 


\section{APPENDIX A: PROOFS}

\section{PROOF OF PROPOSITION 1}

We prove the proposition by deducing the optimal dynamic land redistribution scheme. Transferring to each beneficiary $i$ a plot of land such that total land is $n^{u}\left(\lambda_{i t}\right)$ guarantees $e_{i t}^{o}=1$. As we can only distribute land of a size $N, \delta_{0}$ amounts to $\delta_{0}=N / n^{u}(1)$. The initial land redistribution can be summarized by

$$
\bar{n}_{i 0}= \begin{cases}n^{u}(1)-n_{-1} & \text { if } i \in\left[0, \delta_{0}\right] \\ -n_{-1} & \text { otherwise }\end{cases}
$$

This results in human capital formation in the following way:

$$
\lambda_{i 1}= \begin{cases}1+h(1) & \forall i \in\left[0, \delta_{0}\right] \\ 1 & \text { otherwise }\end{cases}
$$

In the following period, the proportion $\delta_{0}$ can be expropriated according to $n_{i 1}^{\tau}\left(\lambda_{i 1}\right)=$ $n^{u}(1)-n^{u}(1+h(1))$. (Confiscating more land would result in an education choice $e_{i t}$ below unity, so that child labor would again prevail in beneficiary households. In the worst case, beneficiaries would fall back into the poverty trap, when $\lambda_{i t}<\lambda^{m}$. Thus, the success of the reform would only be temporary.)

Expropriation results in an increase of beneficiaries' human capital intensity. Thus the group $\delta_{0}$ possibly wishes to switch to sector $I$ [see condition (8)]. For all $i \in\left[0, \delta_{0}\right]$ alike we obtain

$$
a_{i 1}= \begin{cases}1 & \text { if } \frac{\lambda_{i 1}}{n_{i 0}-n_{i 1}^{\tau}} \leq\left(\frac{B_{1}}{B_{2}}\right)^{\frac{1}{1-\alpha}} \\ 0 & \text { otherwise. }\end{cases}
$$

Hence expropriation must be made contingent on whether beneficiaries will switch to sector $I$. Applying (7), we obtain for the group of first beneficiaries $\left(i \in\left[0, \delta_{0}\right]\right)$ :

$$
n_{i 1}^{\tau}\left(\lambda_{i 1}, a_{i 1}\right)= \begin{cases}\left(\frac{c^{u}}{B_{1}}\right)^{\frac{1}{1-\alpha}} \cdot\left[1-\left(\frac{1}{1+h(1)}\right)^{\frac{\alpha}{1-\alpha}}\right] & \text { if } a_{i 1}=1 \\ \left(\frac{c^{u}}{B_{1}}\right)^{\frac{1}{1-\alpha}} & \text { otherwise }\end{cases}
$$

so that beneficiaries leaving the land-based sector waive their claim on the plot of land received. Thus the social planner will have the following amount of land at its disposal in period 1:

$$
\int_{i=0}^{\delta_{0}} n_{1}^{\tau}\left(1+h(1), a_{t}(i)\right) \mathrm{d} i=\delta_{0}^{A}\left\{\left[1-\left(\frac{1}{1+h(1)}\right)^{\frac{\alpha}{1-\alpha}}\right]\left(\frac{c^{u}}{B_{1}}\right)^{\frac{1}{1-\alpha}}\right\}+\delta_{0}^{I}\left(\frac{c^{u}}{B_{1}}\right)^{\frac{1}{1-\alpha}},
$$

where $\delta_{0}^{A}=\int_{0}^{\delta_{0}} a_{i t} \mathrm{~d} i$ and $\delta_{0}^{I}=\int_{0}^{\delta_{0}}\left(1-a_{i t}\right) d i$. (The existence of the Lebesque integral can be guaranteed by appropriate tie-breaking rules when households are indifferent between sectors $A$ and $I$.) 
The next land redistribution scheme is

$$
\bar{n}_{i 1}= \begin{cases}-n_{i 1}^{\tau}\left(1+h(1), a_{i 1}\right) & \text { for } i \in\left[0, \delta_{0}\right] \\ n^{u}(1) & \text { for } i \in\left(\delta_{0}, \delta_{0}+\delta_{1}\right] \\ 0 & \text { otherwise, }\end{cases}
$$

where $\delta_{1}=\left[\int_{i=0}^{1} n_{i 1}^{\tau}\left(\lambda_{1}(i), a_{1}(i)\right) d i\right] / n^{u}(1)$. Thus, within fraction $\mu_{1}=\delta_{0}+\delta_{1}$ of the population, all households display $e_{i 1}^{o}=1$. The land transfers in period 1 have to fulfill the constraint

$$
\delta_{1} n^{u}(1)=\int_{0}^{1} n_{i 1}^{\tau}\left(\lambda_{1}(i), a_{1}(i)\right) d i
$$

For the human capital levels in $t=2$ we obtain

$$
\lambda_{i 2}= \begin{cases}1+h(1)[1+h(1)] & \text { for } i \in\left[0, \delta_{0}\right] \\ 1+h(1) & \text { for } i \in\left(\delta_{0}, \mu_{1}\right] \\ 1 & \text { otherwise }\end{cases}
$$

Due to human capital accumulation, beneficiary incomes rise, and the described redistribution mechanism can be repeated. In general, in any period $t$, land redistribution takes the following form:

$$
\bar{n}_{i t}= \begin{cases}-n_{i t}^{\tau}\left(\lambda_{i t}, a_{i t}\right) & \text { for } i \in\left[0, \mu_{t-1}\right] \\ n^{u}(1) & \text { for } i \in\left(\mu_{t-1}, \mu_{t}\right] \\ 0 & \text { otherwise. }\end{cases}
$$

As beneficiaries are left with enough income so that they will choose full education, human capital accumulation evolves according to

$$
\lambda_{i t}= \begin{cases}\sum_{k=0}^{t-\bar{t}_{i}}[h(1)]^{k} & \text { for } t \geq \bar{t}_{i} \\ 1 & \text { for } t<\bar{t}_{i} .\end{cases}
$$

Thus the human capital of beneficiaries continuously rises. The general expropriation rule is given by

$$
n_{i t}^{\tau}=\left\{\begin{array}{c}
\left(\frac{c^{u}}{B_{1}}\right)^{1 /(1-\alpha)}\left[\left(\frac{1}{\sum_{k=0}^{t-\bar{t}_{i}-1}[h(1)]^{k}}\right)^{\alpha /(1-\alpha)}-\left(\frac{1}{\sum_{k=0}^{t-\bar{t}_{i}}[h(1)]^{k}}\right)^{\alpha /(1-\alpha)}\right] \\
\text { if } a_{i t}=1, i \in\left[0, \mu_{t-1}\right] ; \\
\left(\frac{c^{u}}{B_{1}\left\{\sum_{k=0}^{t-\bar{t}_{i}-1}[h(1)]^{k}\right\}^{\alpha}}\right)^{1 /(1-\alpha)} \text { if }\left(a_{i t}=0 \text { and } a_{i, t-1}=1\right), i \in\left[0, \mu_{t-1}\right] \\
0 \quad \text { otherwise. }
\end{array}\right.
$$


The share of the society entitled to obtain $n^{u}(1)$ in a period $t$ is given by

$$
\delta_{t}=\min \left\{\frac{\int_{0}^{1} n_{i t}^{\tau} \mathrm{d} i}{n^{u}(1)}, 1-\mu_{t-1}\right\} .
$$

According to (A.11) we have $\int_{0}^{1} n_{i t}^{\tau} \mathrm{d} i \geq 0$ and thus $\mu_{t} \geq \mu_{t-1}$.

In the final step we have to show that $\mu_{t}$ becomes unity in finite time. This is shown by contradiction.

Suppose that $\mu_{t}<1$ for all $t$ and thus $T$ is not finite. Two cases could occur: $\lim _{t \rightarrow \infty} \mu_{t}<$ 1 or $\lim _{t \rightarrow \infty} \mu_{t}=1$. Choose some arbitrarily small $\theta$ with $N / 2 n^{u}(1)>\varepsilon>0$ and a period $\hat{t}$ such that $\left|\mu_{\hat{t}}-\lim _{t \rightarrow \infty} \mu_{t}\right|<\varepsilon$. Choose some arbitrarily small $\theta$ with $\frac{1}{2}>\theta>0$. According to the expropriation rule, there exists a time period $\hat{\hat{t}}>\hat{t}$ such that $n_{i \hat{i}}<\theta N$ for all $i \in\left[0, \mu_{\hat{t}}\right]$. (Note that the land size required to induce $e^{o}=1$ converges to zero when human capital grows without bounds.)

The available land for households $i \in\left(\mu_{\hat{t}}, 1\right]$ is therefore at least $N\left(1-\theta \mu_{\hat{t}}\right)>N(1-\theta)$. Hence, at least $N(1-\theta) / n^{u}(1)>N / 2 n^{u}(1)>\varepsilon$ households could be allocated a plot $n^{u}(1)$ and these beneficiaries would choose full education. Hence, $\mu_{\hat{t}+1}>\mu_{\hat{t}}+\varepsilon$ and we obtain a contradiction, since $\mu_{\hat{t}+1}>\lim _{t \rightarrow \infty} \mu_{t}$.

\section{PROOF OF PROPOSITION 3}

In all periods $t>0$, all not-yet-supported households own no land $\left(n_{i t}=0\right)$ and display $a_{i t}=0$, because $y^{A}(n=0)=0$. Land reform beneficiaries own a plot of land of size $n^{u}\left(\lambda_{i t}\right)$ and thus consume $c^{u}$. Applying $\tilde{\lambda}=\lambda^{u_{I}}$, we obtain $a_{i t}=0$ in equilibrium if $\lambda_{i t}>\lambda^{u_{I}}$ and $a_{i t}=1$ if $\lambda_{i t}<\lambda^{u_{I}}$. If $\lambda_{i t}=\lambda^{u_{I}}$, household $i$ is indifferent between sector $A$ and sector $I$.

\section{PROOF OF PROPOSITION 4}

A household $i$ will switch to sector $I$ as soon as $\lambda_{i t} / n_{i t}>\left(B_{1} / B_{2}\right)^{1 / 1-\alpha}$. Due to $h(1)>1$, human capital grows infinitely. It follows that in each beneficiary household the human capital-to-land ratio will exceed $\left(B_{1} / B_{2}\right)^{1 / 1-\alpha}$ at a certain point in time. 


\section{APPENDIX B}

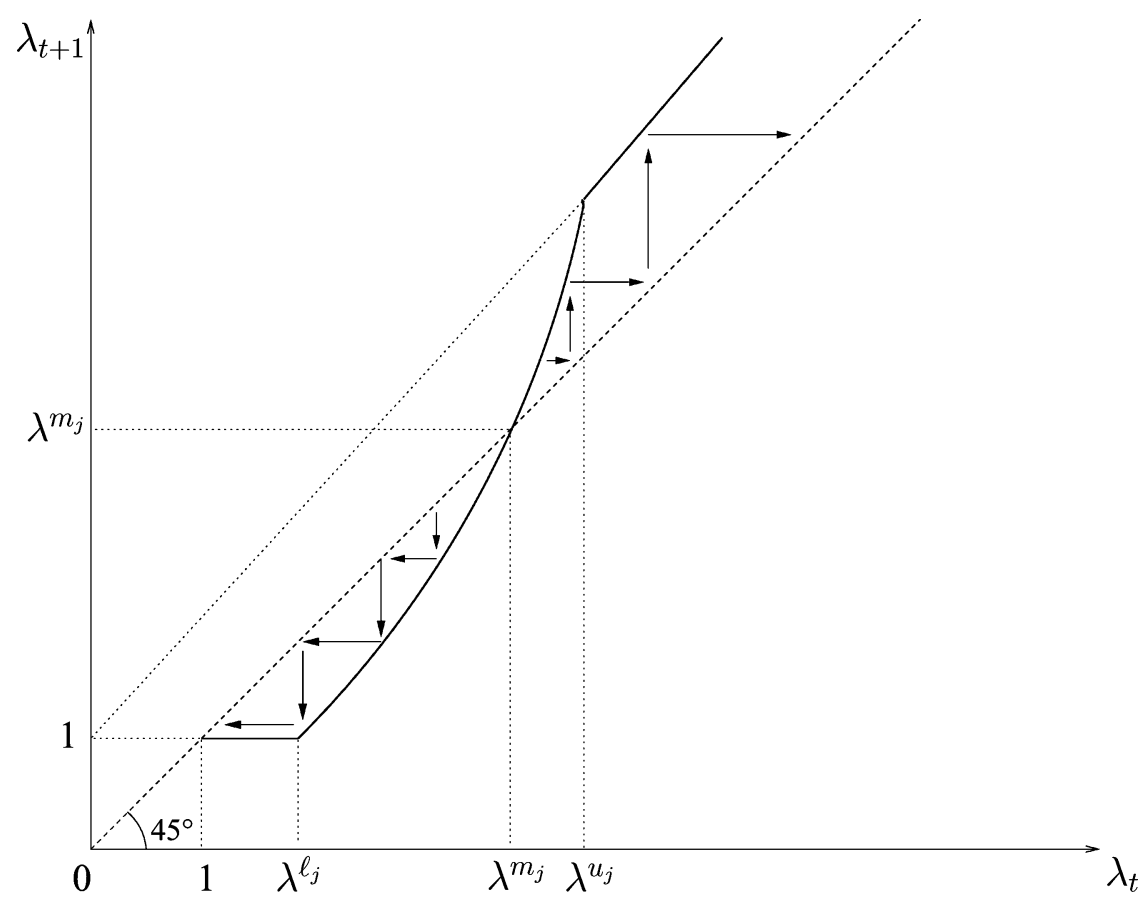

FIGURE B.1. Convex human capital technology where $\lambda^{\ell_{j}}>1,1+h(1) \lambda^{u_{j}}>\lambda^{u_{j}}$, and $h(1)>1$, for $j=\{A, I\}$. The figure is valid for both sectors. However, in sector $A$ we have $\lambda^{\ell_{A}}=\lambda^{\ell_{A}}\left(n_{i t}\right), \lambda^{m_{A}}=\lambda^{m_{A}}\left(n_{i t}\right)$, and $\lambda^{u_{A}}=\lambda^{u_{A}}\left(n_{i t}\right)$, where $\partial \lambda^{k} / \partial n_{i t}<0$ for $k=\left\{\ell_{A}, m_{A}, u_{A}\right\}$; that is, the figure holds for a given amount of land. 